\title{
MCM-41-supported vanadium catalysts structurally modified with Al or Zr for thiophene hydrodesulfurization
}

\author{
Yelisbeth Escalante ${ }^{1,2}\left(\mathbb{C}^{\circ} \cdot\right.$ Franklin J. Méndez $^{1,3} \cdot$ Yraida Díaz $^{1} \cdot$ Marcel Inojosa $^{1} \cdot$ Myloa Morgado $^{1} \cdot$ Miguel Delgado $^{4}$. \\ Ernesto Bastardo-González ${ }^{5,6}$ • Joaquín L. Brito ${ }^{1,6}$
}

Received: 30 September 2018 / Accepted: 26 March 2019 / Published online: 3 April 2019

(c) The Author(s) 2019

\begin{abstract}
Vanadium catalysts supported on $\mathrm{Al}(\mathrm{Zr})-\mathrm{MCM}-41$-type materials were prepared by impregnation. Textural and structural properties, elemental composition and electronic structure were determined by $\mathrm{N}_{2}$ physisorption, small-angle XRD, SEMEDX and UV-vis DRS, respectively. Al-containing materials showed mostly of Al framework and a small fraction of $\mathrm{Al}$ extra-framework species. Zr-containing materials presented almost exclusively small clusters of $\mathrm{Zr}_{\mathrm{x}} \mathrm{O}_{\mathrm{y}}$ covering the MCM41 matrix. Vanadium catalysts, showed the presence of isolated $\mathrm{V}^{5+}$ species and to a lesser extent polymeric chains likely as small crystallites of $\mathrm{V}_{2} \mathrm{O}_{5}$. The catalytic results revealed that VAlM30 catalyst, characterized by a Si/Al atomic ratio of 30 , was the most active in thiophene hydrodesulfurization, which could be associated to better textural properties and high dispersion of the vanadium species.
\end{abstract}

Keywords Aluminosilicates $\cdot$ Hydrodesulfurization $\cdot$ Modified-MCM-41 $\cdot$ Vanadium catalysts $\cdot$ Zirconiosilicates

\section{Introduction}

The demand for crude oil worldwide has generated a reduction of light crude oil reserves and an increase of heavy and extra-heavy crude oils production. The extra-heavy fractions of crude oil are characterized by high contents of compound containing S, N and heavy-metals, such as $\mathrm{Ni}$ and

Yelisbeth Escalante

escalanteyc@gmail.com

$\triangle$ Joaquín L. Brito

jbrito@yachaytech.edu.ec

1 Centro de Química, Instituto Venezolano de Investigaciones Científicas, Caracas, Venezuela

2 Instituto de Investigaciones en Tecnología Química, Universidad Nacional de San Luis, Almirante Brown 1455, 5700 San Luis, Argentina

3 Instituto de Física, Universidad Nacional Autónoma de México, Ciudad De México, Mexico

4 Facultad de Ciencias, Universidad de Los Andes, Mérida, Venezuela

5 Departamento de Química, Universidad de Oriente - Núcleo de Sucre, Cumaná, Venezuela

6 School of Chemistry and Engineering, Yachay Tech University, 100119 Urcuquí, Ecuador
V [1]. Sulfur is the most abundant impurity in the crude oil, so that the main aim of a refinery is to produce ultra-clean fuels with low levels of sulfur [2]. The hydrotreating (HDT) processes are extensively used to remove impurities from different streams [1,2].

The most predominant metal in petroleum is vanadium, which is usually present in the form of porphyrins [3]. During HDT processes, the porphyrins are decomposed and the metal is deposited as a sulfide on the catalyst surface causing its permanent deactivation [1, 4]. Although metal deposits are considered as one of the factors responsible for the catalysts deactivation, some authors have reported that these metal sulfides could act as catalytically active sites in the HDT processes [5, 6]. Therefore, the development of vanadium-based catalysts to carry out HDT reactions is considered to be a research area of great interest. A few studies have been reported on the use of vanadium catalysts in the HDT reactions [7, 8]. However, most of them have focused on the vanadium sulfides on bulk-form or supported over the conventional support, as alumina.

Mesoporous molecular sieves, as MCM-41, have been considered as a potential catalytic support in many reactions, including hydrodesulfurization (HDS) reactions [9-11]. The main advantage of these mesoporous materials is the possibility to obtain high dispersion of the active 
phase at high loadings because they possess a well-ordered hexagonal array of uniform mesopores and high surface areas [12-14]. On the other hand, just like in zeolites, the isomorphic substitution of $\mathrm{M}^{x+}$ ions $(x=3+$ or $4+)$ in the mesoporous silica frameworks, induces surface acidity [15, 16] by generation of Brönsted type acid sites. The most of them are based on the Al-containing MCM-41-derivatives, which has been used as support for HDT catalysts $[17,18]$. Transition metal substituted MCM-41 by, e.g., Zr [19], Ti [20] or $\mathrm{Nb}$ [21] have been less studied than Al-containing MCM-41, but have shown some potential applications for hydrotreatment reactions.

In the present work, it is reported a facile synthesis and characterization of some vanadium-based catalysts supported on MCM-41, pure and structurally modified with Al and $\mathrm{Zr}$. The catalytic tests on thiophene HDS at atmospheric pressure were also carried out because, to our best knowledge, these metal combinations have not been evaluated in sulfur removal reactions.

\section{Experimental}

Tetraethylorthosilicate (TEOS, 98\%, Sigma-Aldrich), fumed silica $\left(\mathrm{SiO}_{2}\right.$, particle size $=0.2-0.3 \mu \mathrm{m}$, surface area $=200 \pm 35 \mathrm{~m}^{2} / \mathrm{g}$, Sigma-Aldrich), tetramethylammonium hydroxide solution (TMAOH, $25 \%$ in $\mathrm{H}_{2} \mathrm{O}$, Sigma-Aldrich), cetyltrimethylammonium bromide (CTMAB, $\geq 98 \%$, Sigma-Aldrich), sodium hydroxide ( $\mathrm{NaOH}, 98 \%$, Riedel-de Haen), sulfuric acid $\left(\mathrm{H}_{2} \mathrm{SO}_{4}, \geq 97.5 \%\right.$, Sigma-Aldrich), aluminum (III) isopropoxide ( $\mathrm{Al}\left[\mathrm{OCH}\left(\mathrm{CH}_{3}\right)_{2}\right]_{3}, 98 \%$, Sigma-Aldrich), zirconium (IV) propoxide solution $\left(\mathrm{Zr}\left(\mathrm{OCH}_{2} \mathrm{CH}_{2} \mathrm{CH}_{3}\right)_{4}, 70 \%\right.$ in propanol, Sigma-Aldrich), isopropanol $\left(\left(\mathrm{CH}_{3}\right)_{2} \mathrm{CHOH}\right.$, 98\%, Sigma-Aldrich), ethanol $\left(\mathrm{CH}_{3} \mathrm{CH}_{2} \mathrm{OH}, 99.8 \%\right.$, SigmaAldrich), ammonium metavanadate $\left(\mathrm{NH}_{4} \mathrm{VO}_{3}, 99 \%\right.$, SigmaAldrich) and deionized water were used during support and catalyst preparations. All chemicals were used as received without further purification.

\section{Synthesis of MCM-41}

Pure siliceous MCM-41 material was synthesized according to a previously published procedure [18]. In a typical experiment, $\mathrm{NaOH}$ was dissolved in deionized water and added to fumed $\mathrm{SiO}_{2}$, under magnetic agitation at $70{ }^{\circ} \mathrm{C}$. An aqueous micellar solution was prepared using TMAOH and CTMAB. After that, the $\mathrm{NaOH} / \mathrm{SiO}_{2}$ solution was added to the micellar solution and the $\mathrm{pH}$ adjusted to 9 with diluted $\mathrm{H}_{2} \mathrm{SO}_{4}$. The resulting gel was kept under magnetic agitation for 2 additional hours. The mixture was aged at room temperature for $24 \mathrm{~h}$ without stirring, filtered, washed, dried, pulverized and calcined at $550{ }^{\circ} \mathrm{C}$ for $8 \mathrm{~h}$. The molar gel composition is shown in Table 1.

\section{Synthesis of Al- and Zr-modified MCM-41}

$\mathrm{Al}$ - and $\mathrm{Zr}$-modified MCM-41 supports were prepared using the procedure in the same report [18]. Aluminum (III) isopropoxide or zirconium (IV) propoxide was dispersed in an isopropanol solution at about $70{ }^{\circ} \mathrm{C}$. After that, TEOS was added to a dry ethanol solution. The TEOS solution was added to solution containing Al- or $\mathrm{Zr}$-ions and kept under magnetic stirring during $5 \mathrm{~h}$ in reflux. The obtained solution was added dropwise to the micellar solution, as previously described it. The mixture was aged at room temperature for $24 \mathrm{~h}$ without stirring, filtered, washed, dried, pulverized and calcined at $550{ }^{\circ} \mathrm{C}$ for $8 \mathrm{~h}$. The molar gel composition and nominal $\mathrm{Si} / \mathrm{M}$ ratios are also shown in Table 1.

\section{Vanadium-based catalysts preparation}

Supported vanadium catalysts with $5 \mathrm{wt} \% \mathrm{~V}$ were prepared by impregnation using an excess volume of ammonium metavanadate aqueous solution. The obtained suspensions were treated under reduced pressure using rotary-evaporation equipment at $60{ }^{\circ} \mathrm{C}$ and $60 \mathrm{rpm}$ until complete solvent removal. The solid was dried at room temperature and calcined at $500{ }^{\circ} \mathrm{C}$ for $4 \mathrm{~h}$.
Table 1 Gel molar compositions to prepare pure and $\mathrm{Al}$ - or $\mathrm{Zr}$-modified MCM41-mesoporous supports and catalysts

\begin{tabular}{|c|c|c|c|}
\hline Supports ${ }^{\mathrm{a}}$ & Gel molar composition & $\begin{array}{l}\text { Nominal Si/M } \\
\text { ratio }\end{array}$ & Catalysts $^{\mathrm{b}}$ \\
\hline M & $0.2 \mathrm{SiO}_{2}: 0.05 \mathrm{CTMABr}: 0.4 \mathrm{NaOH}: 8 \mathrm{H}_{2} \mathrm{O}$ & - & VM \\
\hline AlM70 & 0.2TEOS:0.0028Al:0.05CTMABr: $4 \mathrm{H}_{2} \mathrm{O}: 0.9\left(\mathrm{CH}_{3}\right)_{2} \mathrm{CHOH}$ & 70 & VAlM70 \\
\hline AlM30 & 0.2TEOS:0.0068Al:0.05CTMABr: $4 \mathrm{H}_{2} \mathrm{O}: 0.9\left(\mathrm{CH}_{3}\right)_{2} \mathrm{CHOH}$ & 30 & VAlM30 \\
\hline ZrM40 & 0.2TEOS:0.005Zr:0.05CTMABr: $4 \mathrm{H}_{2} \mathrm{O}: 0.9\left(\mathrm{CH}_{3}\right)_{2} \mathrm{CHOH}$ & 40 & VZrM40 \\
\hline ZrM20 & 0.2TEOS:0.010Zr:0.05CTMABr: $4 \mathrm{H}_{2} \mathrm{O}: 0.9\left(\mathrm{CH}_{3}\right)_{2} \mathrm{CHOH}$ & 20 & VZrM20 \\
\hline
\end{tabular}

${ }^{\mathrm{a}} \mathrm{M}=\mathrm{MCM}-41 ; \mathrm{AlMx}=\mathrm{Al}-\mathrm{MCM}-41 x(x=\mathrm{Si} / \mathrm{Al}=70$ and 30$)$ and $\mathrm{ZrMy}=\mathrm{Zr}-\mathrm{MCM}-41 y(y=\mathrm{Si} / \mathrm{Zr}=40$ and 20)

${ }^{\mathrm{b}} \mathrm{VM}, \mathrm{VAlM} x$ and VZrMy = supported V-containing catalysts with a V nominal content of $5 \mathrm{wt} \%$ 


\section{Supports and catalysts nomenclature}

The supports were denoted as M (MCM-41), AlMx (AlMCM-41 $x$, where $x=\mathrm{Si} / \mathrm{Al}=70$ or 30 ) and $\mathbf{Z r M y}(\mathrm{Zr}-$ MCM-41y, where $\mathrm{y}=\mathrm{Si} / \mathrm{Zr}=40$ or 20 ), while the catalysts were denoted as VM, VAIMx and VZrMy, where the $\mathrm{V}$-containing catalysts presented a $\mathrm{V}$ nominal content of 5 $\mathrm{wt} \%$.

\section{Physicochemical characterization}

The textural analysis was carried out using a MicromeriticsASAP 2010 automatic analyzer at liquid $\mathrm{N}_{2}$ temperature. The solids were previously degassed overnight under vacuum at $60{ }^{\circ} \mathrm{C}$. The micrographs and elemental composition were obtained using a scanning electron microscope model FEI Quanta 250 coupled to an energy-dispersive X-ray analyzer EDAX model Octane SDD. Small-angle X-ray diffraction (SA-XRD) patterns were obtained using a Siemens D5005 diffractometer with $\mathrm{CuK} \alpha$ radiation and step rate of $0.025 \%$ s. Ultraviolet-visible diffuse reflectance spectra (UV-vis DRS) were recorded using a Perkin Elmer Lambda 35 spectrophotometer. The measurements were done using $\mathrm{BaSO}_{4}$ as standard.

\section{Catalytic test}

The thiophene HDS reactions were carried out in a fixedbed Pyrex ${ }^{\circledR}$ reactor with $250 \mathrm{mg}$ of catalyst at $350{ }^{\circ} \mathrm{C}$, atmospheric pressure and a volumetric flow of $100 \mathrm{~mL} /$ min $\left(2.27 \mathrm{~mol} \%\right.$ thiophene in $\left.\mathrm{H}_{2}\right)$. Prior to reaction, the mesoporous catalysts were activated in situ under a flow of $100 \mathrm{~mL} / \mathrm{min}\left(1.00 \mathrm{vol} . \% \mathrm{CS}_{2}\right.$ in $\left.\mathrm{H}_{2}\right)$ for $2 \mathrm{~h}$ at $350{ }^{\circ} \mathrm{C}$. The reaction products were analyzed using a gas chromatograph equipped with a FID, with sampling of the gas effluent for analysis at $12 \mathrm{~min}$ intervals. The stabilization (or steady state catalytic activities) was obtained when four consecutive measurements gave the same conversion $(\sim 2 \mathrm{~h})$. The catalytic activity is reported as pseudo-first-order rate constant for thiophene disappearance in units of milimoles of thiophene converted to products per gram of catalyst per minute. Generally, the reproducibility was better than $10 \%$.

\section{Results and discussion}

Nitrogen physisorption isotherms of the synthesized supports are presented in Fig. 1. The isotherm of pure silica MCM-41 corresponds to a Type-IV isotherm with a welldefined step at a relative pressure between 0.3 and 0.4 , demonstrating the formation of a uniform mesoporous material. On the other hand, the isotherms of the modified supports were similar to that of the parent MCM-41,
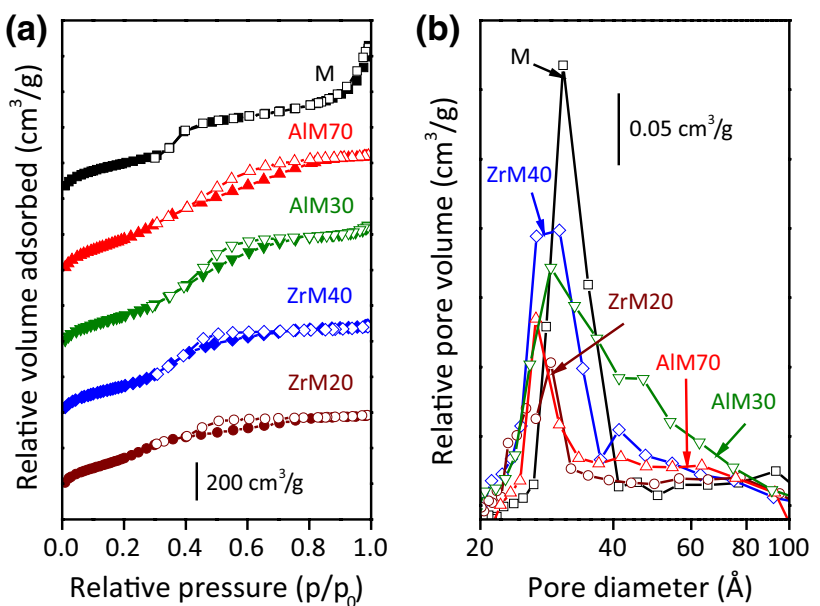

Fig. $1 \mathrm{~N}_{2}$ physisorption isotherms (a) and pore size distributions (b) of unmodified and modified mesoporous supports. Full and unfilled symbols represent the adsorption and desorption branches, respectively. The samples were degassed under vacuum and measured using a Micromeritics-ASAP 2010 automatic analyzer at liquid $\mathrm{N}_{2}$ temperature

indicating that a mesoporous structure was obtained after $\mathrm{Al}$ - and $\mathrm{Zr}$-incorporation. The modified supports also presented smaller overall amount of adsorbed $\mathrm{N}_{2}$ and an additional Type-H3 hysteresis loop. This can be ascribed to the increase in the materials' density due to structural incorporation of metal species. Furthermore, the existence of such a hysteresis loop might indicate that some structural defects are formed in the hexagonal channels matrix. The $\mathrm{N}_{2}$ physisorption isotherms of their respective mesoporous catalysts presented similar forms (not shown).

The supports showed high specific surface areas; these values are close to or slightly higher than $1000 \mathrm{~m}^{2} / \mathrm{g}$ (see Table 2). Vanadium impregnation resulted in a decrease of specific surface area and a decrease of pore volume, which becomes more pronounced in materials containing zirconium. These results suggest the presence of some metal species covering the structure of the MCM-41 that can cause pore plugging. On the other hand, the MCM41 showed a narrow distribution of pore sizes, indicating uniformity in the size of pores (Fig. 1b). The modified supports presented a bimodal distribution of pore sizes, with pore sizes prevailing around $30 \AA$. According to the literature, these results show that there is a decrease in the hexagonal-type mesopores arrays density, due to the development of a new family of extra-structural pores of size above $40 \AA$, which can be generated by the presence of small metal oxide crystals dispersed in the matrix of MCM-41 [22].

The textural properties of the mesoporous catalysts are also shown in Table 2. A significant decrease in the specific surface area and pore volume were also observed. This

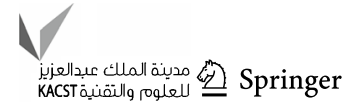


Table 2 Textural and structural characteristics and $\mathrm{Si} / \mathrm{M}$ atomic ratios of supports and catalysts

\begin{tabular}{lcllllll}
\hline Sample $^{\mathrm{a}}$ & $S_{\text {BET }}\left(\mathrm{m}^{2} / \mathrm{g}\right)^{\mathrm{b}}$ & $V_{\mathrm{p}}\left(\mathrm{cm}^{3} / \mathrm{g}\right)^{\mathrm{c}}$ & $D_{\mathrm{p}}(\AA)^{\mathrm{d}}$ & $(\mathrm{Si} / \mathrm{M} \pm \sigma)^{\mathrm{e}}$ & $d_{100}(\AA)^{\mathrm{f}}$ & $a_{0}(\AA)^{\mathrm{g}}$ & $\delta(\AA)^{\mathrm{h}}$ \\
\hline M & 1036 & 1.43 & 31 & & 40.9 & 47.2 & 16 \\
AlM70 & 1168 & 1.21 & 30 & $(30.2 \pm 3.2)$ & 41.1 & 47.4 & 17 \\
AlM30 & 1025 & 1.21 & 30 & $(15.1 \pm 0.9)$ & 42.8 & 49.4 & 19 \\
ZrM40 & 948 & 0.93 & 30 & $(44.6 \pm 5.6)$ & 40.7 & 47.0 & 17 \\
ZrM20 & 1001 & 0.78 & 29 & $(20.2 \pm 1.0)$ & 36.1 & 41.7 & 13 \\
VM & 672 & 0.97 & 28 & & & & \\
VAlM70 & 566 & 0.33 & 26 & & & & \\
VAlM30 & 678 & 0.51 & 30 & & & & \\
VZrM40 & 486 & 0.31 & 29 & & & & \\
VZrM20 & 593 & 0.45 & 29 & & & & \\
\hline
\end{tabular}

${ }^{\mathrm{a}} \mathrm{M}=\mathrm{MCM}-41 ; \mathrm{AlM} x=\mathrm{Al}-\mathrm{MCM}-41 x(x=\mathrm{Si} / \mathrm{Al}=70$ and 30$)$ and $\mathrm{ZrM} y=\mathrm{Zr}-\mathrm{MCM}-41 y(y=\mathrm{Si} / \mathrm{Zr}=40$ and 20). VM, VAlM $x$ and $\mathrm{VZrM} y=$ supported $\mathrm{V}$-containing catalysts with a $\mathrm{V}$ nominal content of $5 \mathrm{wt} \%$

${ }^{\mathrm{b}} S_{\mathrm{BET}}$, specific surface area determined by the BET method

${ }^{\mathrm{c}} V_{\mathrm{p}}$, total pore volume obtained at relative pressure of 0.98

${ }^{\mathrm{d}} D_{\mathrm{p}}$, pore diameter determined from the desorption branch of the isotherms by the BJH

${ }^{\mathrm{e}}$ Atomic ratio $\mathrm{Si} / \mathrm{M}$ (with $\mathrm{M}=\mathrm{Zr}$ or $\mathrm{Al}$ ) determined by SEM-EDX and standard deviation $(\sigma)$ values

${ }^{\mathrm{f}} d_{100}=$ interplanar spacing

${ }^{g}$ Lattice parameter $\left(a_{0}\right)$ for a hexagonal structure: $a_{0}=2 d_{100} / \sqrt{ } 3$

${ }^{\text {h}}$ Pore wall thickness $(\delta)$ estimated by $\delta=a_{0}-D_{\mathrm{p}}$ decrease could be due to pore blocking by metal species plus a dilution effect of the support by the supported species $[9,10]$. The supported vanadium catalysts with lower $\mathrm{Si} / \mathrm{M}$ ratios showed better textural properties compared to higher Si/M ones. These tendencies could be indicative that the dispersion of vanadium species was favored on modified supports with lower $\mathrm{Si} / \mathrm{M}$ ratios.

The chemical compositions (Table 2), presented as $\mathrm{Si} / \mathrm{M}$ atomic ratios $(\mathrm{M}=\mathrm{Al}$ or $\mathrm{Zr})$, of selected mesoporous supports were obtained by SEM-EDX. SEM micrographs and their respective EDX spectra for the AlM70 and ZrM20 supports showed some spherical particles that are formed by $\mathrm{Si}$, $\mathrm{O}$ and $\mathrm{Al}$ (or $\mathrm{Zr}$ ), as it is shown in top and bottom of Fig. 2a and $b$, respectively. It was also found that the experimental $\mathrm{Si} / \mathrm{Zr}$ ratios are close to the nominal values. On the contrary, such closeness was not observed for $\mathrm{Al}$ modified-supports. The differences observed can be associated to the solubility of the precursors; the $\mathrm{Zr}$-precursor is more soluble than the $\mathrm{Al}$ one, suggesting that some $\mathrm{Al}$ atoms could precipitate on the support surface forming $\mathrm{Al}$ rich-aggregates. On the other hand, the modified supports, prepared from TEOS in alcoholic medium, showed spherical morphology, while the MCM-41 obtained from fumed silica resulted in irregularly shaped particles (not shown). Thus, it can be said that the silica spheres are obtained from the hydrolysis of tetraalkoxysilanes in a mixture of low-boiling alcohols, as previously reported [23].

The well-ordered mesoporous structure of MCM-41 was also confirmed from its SA-XRD pattern (Fig. 3). The unmodified support exhibited a relatively intense reflection at $2.3^{\circ}(2 \theta)$ and two weaker signals between 3 and $5^{\circ}(2 \theta)$ assigned, respectively, to (100), (110) and (200) planes, characteristic of a hexagonal structure [12, 13]. The Aland $\mathrm{Zr}$-incorporation produced a decrease of the intensity of (100) plane and an incomplete disappearance of (110)and (200)-reflections. These results can be attributed to distortions in the hexagonal structure due to the isomorphic substitution of $\mathrm{Si}$ atoms by $\mathrm{Al}$ (or $\mathrm{Zr}$ ) ones. It can be also seen a shift of (100)-reflection towards lower $2 \theta$ values for the Al-modified supports, indicating an expansion of the structure, confirmed by the increment of pore wall thickness, lattice parameter and interplanar distance, as it can be seen in Table 2. Several authors have reported that the increased wall thickness is a strong evidence of metal incorporation into the MCM-41 framework [17, 18, 24]. On the contrary, $\mathrm{Zr}$-containing materials showed a different behavior; the (100)-reflection was shifted to higher $2 \theta$ values with increasing $\mathrm{Zr}$ content. It was also observed a decrease of the structural parameters, in the material with higher $\mathrm{Zr}$ content. These results could indicate that at low $\mathrm{Si} / \mathrm{Zr}$ ratios, $\mathrm{Zr}$ atoms prefer to form extra-framework type species instead of replacing the Si atoms; the UV-vis DRS results confirm it (see below). According to the results, it can be inferred that there are different $\mathrm{Si} / \mathrm{M}$ ratios to obtain materials with optimal parameters, which has been related to thermal stability of these materials [25].

UV-vis DRS is a sensitive technique to study metal coordination, for $\mathrm{Al}$ - and $\mathrm{Zr}$-incorporated in zeolites or MCM41 structures [26-28] or supported vanadium catalysts [29, 30]. The DR spectra of Al-containing samples presented an 

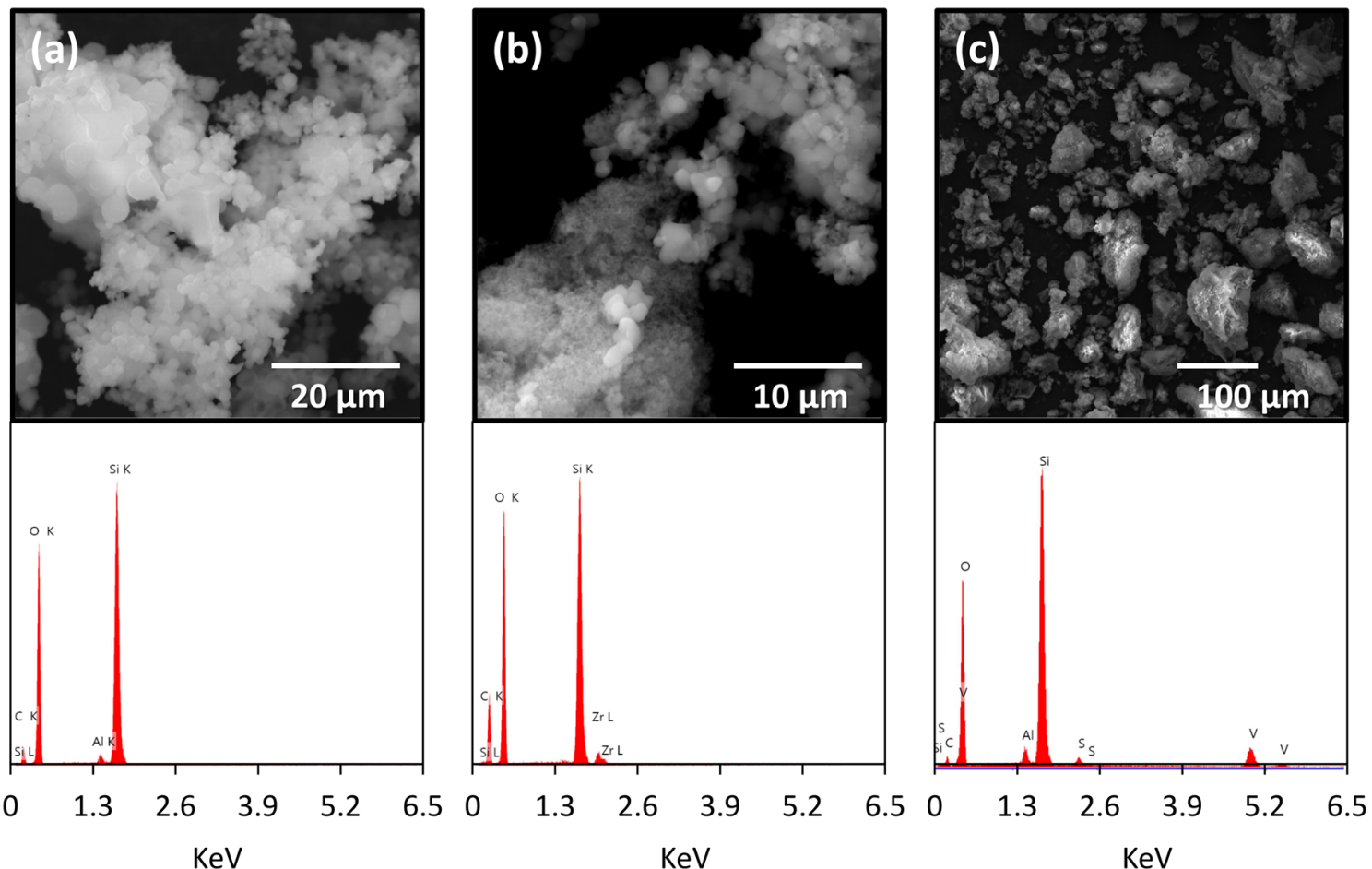

Fig. 2 SEM (top) micrographs and elemental analysis spectra (EDX, bottom) of the ZrM40 (a) and AlM30 (b) supports and sulfided VAlM30 catalyst (c). The analyses were carried out using a FEI Quanta 250 SE microscope coupled to an EDAX model Octane SDD analyzer

Fig. 3 Small-angle X-ray diffraction patterns of the mesoporous supports. The diffractograms were obtained using a Siemens D5005 diffractometer with $\mathrm{Cu} \mathrm{K} \alpha$ radiation

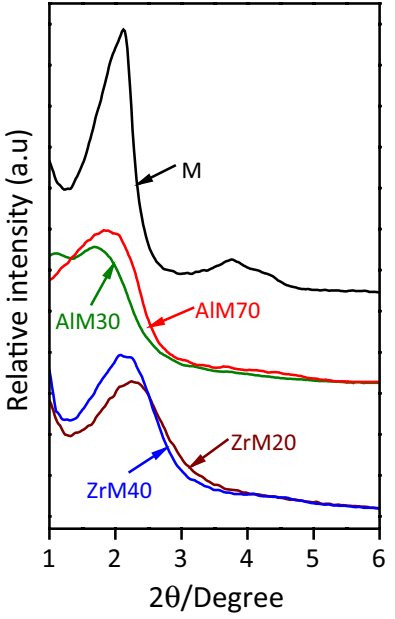

intense band at $240 \mathrm{~nm}$ (not shown), which increases with $\mathrm{Al}$-content and can be attributed to ligand-metal charge transfer (LMCT) $\mathrm{O}^{2-}$ to $\mathrm{Al}^{3+}$ in $\mathrm{Al}$ atoms with tetrahedral coordination. However, some authors have also reported that Al-framework species can be characterized by the presence of a band at $220 \mathrm{~nm}$ [27]. It is possible that the broad band at $240 \mathrm{~nm}$ in the spectra involves both $\mathrm{Al}$ framework and other types of aluminum species with different states of coordination. It was also observed a small contribution of $\mathrm{Al}$ atoms with octahedral coordination by a low intensity broad band centered at $280 \mathrm{~nm}$ [26], formed by surface metal migration.
On the other hand, Zr-containing samples presented a single band at $240 \mathrm{~nm}$, which increases with $\mathrm{Zr}$ content. Some researchers have suggested that LMCT around $220 \mathrm{~nm}$ are probably due to the presence of tetrahedral $\mathrm{Zr}(\mathrm{IV})$ species [31-33]. The adsorption bands above $240 \mathrm{~nm}$ have been assigned to the LMCT $\mathrm{O}^{2-}$ to $\mathrm{Zr}^{4+}$, with $\mathrm{Zr}$ in low coordination state, either isolated or in small $\mathrm{Zr}_{\mathrm{x}} \mathrm{O}_{\mathrm{y}}$ nanoclusters inside the silica framework $[31,34,35]$. The DRS and SAXRD results confirm the presence of $\mathrm{Zr}_{x} \mathrm{O}_{y}$ nanoclusters partially covering the modified-support; however, these $\mathrm{Zr}_{x} \mathrm{O}_{y}$ nanoclusters were not detected by wide angle XRD (WA-XRD, not shown), indicating highly dispersed species.

It is well known that $\mathrm{V}^{5+}$ at tetrahedral coordination sites absorbs between 240 and $350 \mathrm{~nm}$, at square pyramidal coordination between 350 and $450 \mathrm{~nm}$ and at octahedral coordination between 450 and $600 \mathrm{~nm}[36,37]$. The broad band centered at $260 \mathrm{~nm}$ (Fig. 4) is due to the presence of isolated tetrahedral $\mathrm{V}^{5+}$ species that possess the ability of coordinatively bind to $\mathrm{H}_{2} \mathrm{O}$ molecules from the atmosphere, resulting in color changes in the solids and broadened bands in the DR spectra [30]; the widening of this band may also be due to the contribution of the heteroatoms ( $\mathrm{Al}$ or $\mathrm{Zr}$ ). Furthermore, it was also observed a broad band centered at $430 \mathrm{~nm}$, which can be assigned to $\mathrm{V}^{5+}$ species with square pyramidal coordination. However, the widening of this band could be indicating the presence of polymeric chains and even small $\mathrm{V}_{2} \mathrm{O}_{5}$ crystallites $[30,36]$. It should be noted that $\mathrm{V}_{2} \mathrm{O}_{5}$ was 
Fig. 4 UV-vis diffuse reflectance spectra of the unmodified and modified, supported vanadium-based catalysts. The spectra were recorded using a Perkin Elmer Lambda $35 \mathrm{spec}$ trophotometer

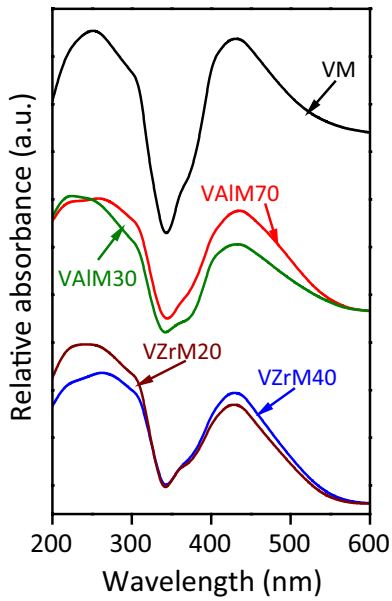

not detected by WA-XRD (not shown), which means that the $\mathrm{VO}_{\mathrm{x}}$ species are highly dispersed.

The experimental results reflected the presence of different $\mathrm{V}^{5+}$ species which could depend on the nature of the mesoporous supports (see Scheme 1). Small $\mathrm{V}_{2} \mathrm{O}_{5}$ nanoclusters could predominate when the $\mathrm{V}$ is supported on the unmodified MCM-41 (Scheme 1a), while isolated tetrahedral or polymeric chains of $\mathrm{V}^{5+}$ oxides could be predominating when $\mathrm{V}$ is supported on the Al-MCM-41 (Scheme 1b) or Zr-MCM-41 (Scheme 1c), respectively.

The catalytic activities in the steady state of the sulfided catalysts are presented in Fig. 5a. In this figure, it can be seen that the sulfided catalyst supported on AlM30 (denoted as VAlM30) exhibited the highest catalytic activity. This behavior may be explained because VAlM30 catalyst showed better textural properties (specific surface area and pore volume) as compared to the other catalysts (see values in Table 2). On the other hand, it is well known that Al-incorporation into MCM-41-framework provides increased number of (and stronger) acid sites, when it is compared with unmodified support, allowing a better dispersion of the $\mathrm{V}$ species [17]. It is possible that, in the VAlM30 catalyst, an adequate number of active sites have been generated to disperse efficiently vanadium species, which is reflected in the catalytic performance of this catalyst. The VAIM30 catalyst was analyzed by SEM-EDX after presulfidation (Fig. 2c) and its elemental analysis (bottom Fig. 2c) revealed the presence, as it was expected, of $\mathrm{Si}, \mathrm{Al}$ and $\mathrm{O}$, as well as $\mathrm{V}$ and $\mathrm{S}$, indicating the possible existence of a sulfided phase of vanadium. Although the unsupported catalyst presented $\mathrm{V}_{2} \mathrm{O}_{5}$ characteristic signals even after the presulfidation step (result not shown), it
Scheme 1 Different V-based species observed in the unmodified and modified catalysts. (a) VM, (b) VAlMx and (c) VZrMy
Isolated species

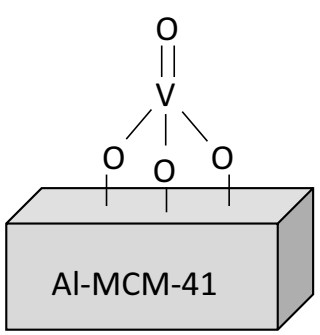

Polymeric chains

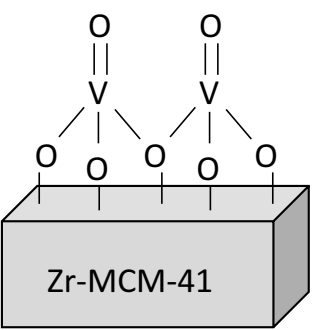

Fig. 5 Catalytic activities in the steady state (a) and selectivities (b) during the thiophene HDS reaction using unmodified and modified supported vanadiumbased mesoporous catalysts. The catalysts were presulfided at $350{ }^{\circ} \mathrm{C}$ with a $\mathrm{CS}_{2} / \mathrm{H}_{2}$ mixture and the reaction tests were carried out at atmospheric pressure and $350{ }^{\circ} \mathrm{C}$, using $250 \mathrm{mg}$ of catalyst and a molar composition of thiophene of $2.27 \mathrm{~mol} \%$ in $\mathrm{H}_{2}$ (a)

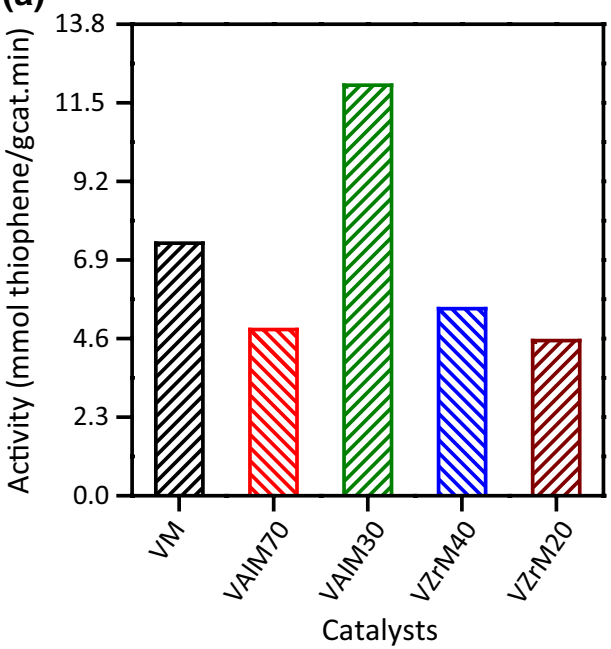

(b)

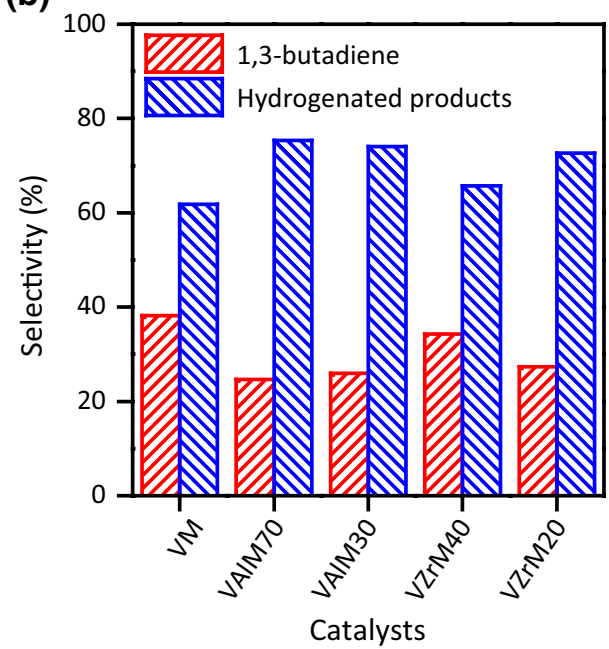


also showed an intense signal at $44.1^{\circ}(2 \theta)$ that could be assigned to any one of a family of vanadium sulfides of the $\mathrm{V}_{x} \mathrm{~S}_{y}$ type. The observed diffraction signal indicates that the V-based catalysts, under presulfidation conditions, could become partially sulfurized to $\mathrm{V}_{x} \mathrm{~S}_{y}$ phases, which are probably responsible for the observed catalytic activity.

The catalytic activity did not appear to be positively influenced by $\mathrm{Zr}$-modification, as both $\mathrm{Zr}$-modified catalysts showed lower performance than unmodified catalyst, even the VZrM20 catalyst which has shown a high dispersion of $\mathrm{V}$ species. This is possibly caused by their low pore volume that can result in pore plugging. It has been reported that the Zr-containing MCM-41 materials have a total acidity comparable to zeolites and, even higher than Al-modified MCM41 [34]. However, as the $\mathrm{Zr}^{4+}$ ions are unable to incorporate additional hydroxyl groups, those materials have very low acidity of the Brönsted type, which could explain the low catalytic activity. It is probable that the Lewis acid sites are not appropriate to effectively disperse the V species.

The thiophene HDS reaction follows two main pathways, as can be seen in Scheme 2 [38]: (1) direct thiophene hydrogenation (denoted as HYD route) leading to tetrahydrothiophene (THT) and, (2) direct C-S scission (denoted as DDS route) to form 1,3-butadiene (BD). Both THT and BD are transient intermediaries that could or could not be present in the final products. 1-butene (BE), cis- (cBE) and trans2-butene (tBE) are the subsequent products that may eventually be hydrogenated to form butane (BA).

The selectivities of all V-based catalysts (Fig. 5b) were expressed as the formation of the DDS product (BD) and the sum of all formed hydrogenated products $(\mathrm{BE}+\mathrm{cBE}+\mathrm{tBE}+\mathrm{BA})$, because the main product of the HYD route (THTH) was not observed. It can be inferred that the evaluated reaction followed exclusively the DDS route. Despite this, it can also be noted that all V-based catalysts showed comparatively high yields of hydrogenated products. Both VAlM70 and VAlM30 catalysts showed lower yield of BD in the final products. These results could be indicative that Al-modified catalysts possess higher hydrogenation capacity compared to unmodified and $\mathrm{Zr}$-modified catalysts. The hydrogenation properties of un-supported vanadium sulfides have already been discussed in the literature [39]. Vanadium sulfides at low $\mathrm{H}_{2}$ pressures promote the DDS route, while under high $\mathrm{H}_{2}$ pressures the HYD route is preferred [7]. Additional studies are required to fully characterize the acidity properties and better understand the observed catalytic behavior; however, the obtained results showed that vanadium sulfides supported on Al-containing MCM-41 could be evaluated for HDS tests using other model molecules, such as dibenzothiophene (DBT), 4-methyldibenzothiophene (MDBT) and 4,6-dimethyldibenzothiophene (DMDBT), which require a previous hydrogenation of the aromatic ring, followed by the removal of the sulfur atom.

\section{Conclusions}

The preparation, characterization and thiophene HDS tests of some vanadium mesoporous catalysts supported on unmodified and $\mathrm{Al}$ - or $\mathrm{Zr}$-modified MCM-41 have been presented. All mesoporous supports showed high specific surface areas and well-defined porous structure. Al-containing MCM-41 materials showed mainly Al-framework and a little contribution of $\mathrm{Al}$ extra-framework, while $\mathrm{Zr}$ modification promoted the formation of $\mathrm{Zr}_{\mathrm{x}} \mathrm{O}_{\mathrm{y}}$ type species. Vanadium oxides species supported on modified materials have also

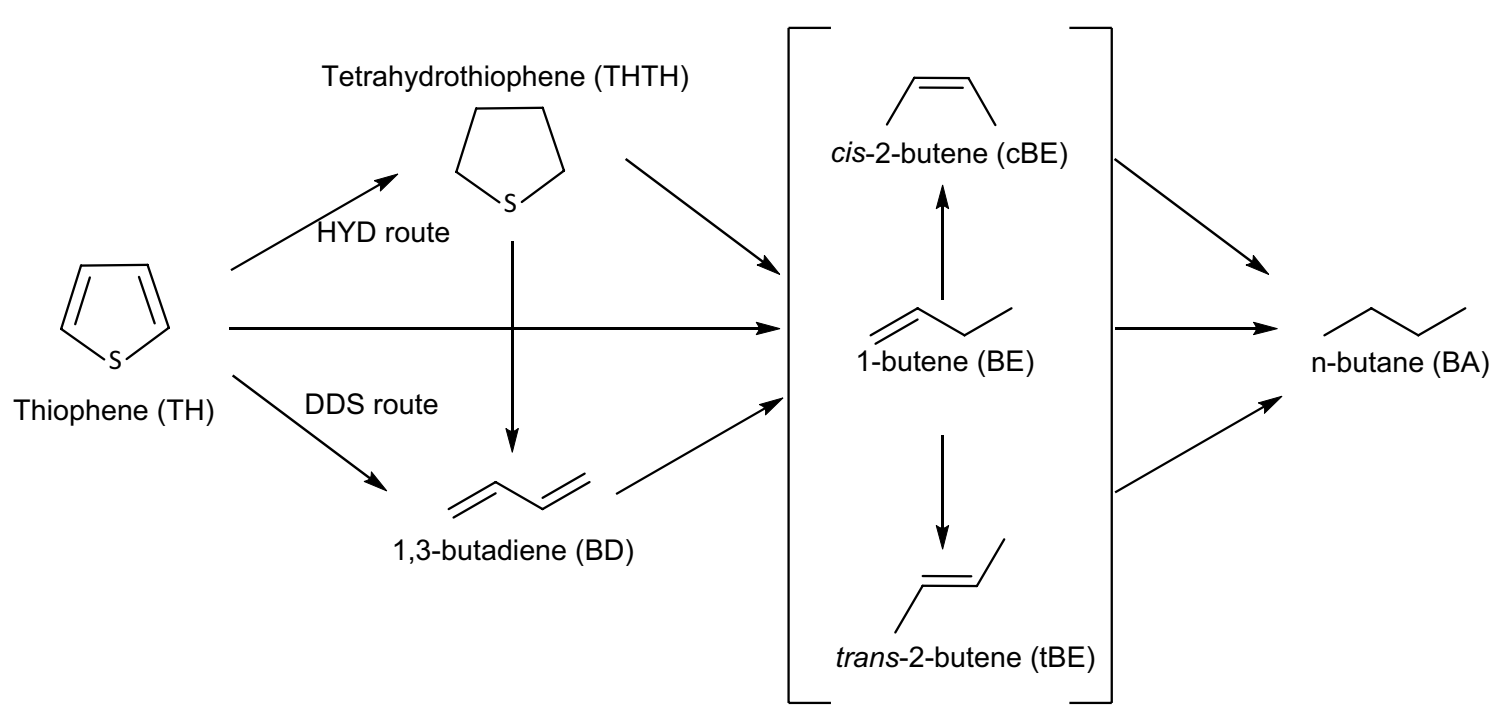

Scheme 2 Reaction pathways of the thiophene HDS [38]

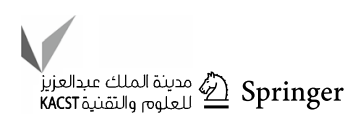


been obtained. However, the dispersion of those vanadium species depended of the support nature and was favored on modified supports with lower $\mathrm{Si} / \mathrm{M}$ ratios. The catalytic test revealed that the VAIM30 catalyst showed highest thiophene conversion that was associated to its good textural and structural properties and the high $\mathrm{V}$ dispersion, which in turn leads to a greater dispersion of the sulfided metal species. Aluminosilicates-supported vanadium catalysts showed higher formation of the hydrogenated products. Thus, it is considered that Al-MCM-41-supported V sulfides catalysts could be promising candidates for deep HDS, where it is required new materials with good hydrogenating properties.

Acknowledgements The authors would like to acknowledge financial support from Fondo Nacional de Ciencia, Tecnología e Innovación (FONACIT) through G-2000001537 project. The authors also thank Laboratorio Nacional de Difracción de Rayos X (LAB-97000821 project) from ULA and Laboratorio de Fotoquímica and Unidad de Microscopía from IVIC for their technical assistances in the SA-XRD, UV-vis DRS and SEM-EDX analysis.

Open Access This article is distributed under the terms of the Creative Commons Attribution 4.0 International License (http://creativeco mmons.org/licenses/by/4.0/), which permits unrestricted use, distribution, and reproduction in any medium, provided you give appropriate credit to the original author(s) and the source, provide a link to the Creative Commons license, and indicate if changes were made.

\section{References}

1. Topsøe H, Clausen BS, Massoth FE (1996) Hydrotreating Catalysis. In: Anderson JR, Boudart M (eds) Catalysis-science and technology. Springer, Berlin, pp 1-269

2. Song C (2003) MCM-41-supported Co-Mo catalysts for deep hydrodesulfurization of light cycle oil. Catal Today 86:211-263. https://doi.org/10.1016/S0920-5861(03)00463-2

3. Goulon J, Retournard A, Friant P, Goulon-Ginet C, Berthe C, Muller JF, Poncet JL, Guilard R, Escalier JC, Neff B (1984) Structural characterization by X-ray absorption spectroscopy (EXAFS/ XANES) of the vanadium chemical environment in Boscan asphaltenes. J Chem Soc, Dalton Trans 1984:1095-1103. https:// doi.org/10.1039/DT9840001095

4. Furimsky E, Massoth F (1999) Deactivation of hydroprocessing catalysts. Catal Today 52:381-495. https://doi.org/10.1016/S0920 -5861(99)00096-6

5. Asaoka S, Nakata S, Shiroto Y, Takeuchi C (1987) Characteristics of vanadium complexes in petroleum before and after hydrotreating. In: Filby RH, Branthaver JF (eds) Metal complexes in fossil fuels. American Chemical Society, Washington, pp 275-289

6. Rana M, Ancheyta J, Maity SK, Rayo P (2005) Characteristics of Maya crude hydrodemetallization and hydrodesulfurization catalysts. Catal Today 104:86-93. https://doi.org/10.1016/j.catto d.2005.03.059

7. Betancourt P, Rives A, Scott CE, Hubaut R (2000) Hydrotreating on mixed vanadium-nickel sulphides: a study of the synergetic effect. Catal Today 57:201-207. https://doi.org/10.1016/S0920 -5861(99)00327-2

8. Betancourt P, Marrero S, Pinto-Castilla S (2013) V-Ni-Mo sulfide supported on $\mathrm{Al}_{2} \mathrm{O}_{3}$ : preparation, characterization and
LCO hydrotreating. Fuel Process Technol 114:21-25. https://doi. org/10.1016/j.fuproc.2013.03.013

9. Wang A, Wang Y, Kabe T, Chen Y, Ishihara A, Qian W (2001) Hydrodesulfurization of dibenzothiophene over siliceous MCM41-supported catalysts. Part I: sulfided Co-Mo catalysts. J Catal 199:19-29. https://doi.org/10.1006/jcat.2000.3148

10. Wang A, Wang Y, Kabe T, Chen Y, Ishihara A, Qian W, Yao P (2002) Hydrodesulfurization of dibenzothiophene over siliceous MCM-41-supported catalysts. Part II: sulfided Ni-Mo catalysts. J Catal 210:319-327. https://doi.org/10.1006/jcat.2002.3674

11. Méndez FJ, Llanos A, Echeverría M, Jáuregui R, Villasana Y, Díaz Y, Liendo-Polanco G, Ramos-García MA, Zoltan T, Brito JL (2013) Mesoporous catalysts based on Keggin-type heteropolyacids supported on MCM-41 and their application in thiophene hydrodesulfurization. Fuel 110:249-258. https://doi. org/10.1016/j.fuel.2012.11.021

12. Beck JS, Vartuli JC, Roth JW, Leonowicz ME, Kresge CT, Schmitt KD, Chu CTW, Olson DH, Sheppard EW, McCullen SB, Higgins JB, Schlenker JL (1992) A new family of mesoporous molecular sieves prepared with liquid crystal templates. J Am Chem Soc 114:10834-10843. https://doi.org/10.1021/ja00053a020

13. Kresge CT, Leonowicz ME, Roth WJ, Vartuli JC, Beck JS (1992) Ordered mesoporous molecular sieves synthesized by a liquid crystal template mechanism. Nature 359:710-712. https://doi. org/10.1038/359710a0

14. Melo RAA, Giotto MV, Rocha J, Urquieta-González EA (1999) MCM-41 ordered mesoporous molecular sieves: synthesis and characterization. Mater Res 2:173-179. https://doi.org/10.1590/ S1516-14391999000300010

15. Hunger M, Schenk U, Breuninger M, Glaser R, Weitkamp J (1999) Characterization of the acid sites in MCM-41-type materials by spectroscopic and catalytic techniques. Microporous Mesoporous Mater 27:261-271. https://doi.org/10.1016/S1387-1811(98)00260 $-1$

16. Chen LF, Noreña LE, Navarrete J, Wang JA (2006) Improvement of surface acidity and structural regularity of Zr-modified mesoporous MCM-41. Mater Chem Phys 97:236-242. https://doi. org/10.1016/j.matchemphys.2005.08.043

17. Klimova T, Calderón M, Ramirez J (2003) Ni and Mo interaction with Al-containing MCM-41 support and its effect on the catalytic behavior in DBT hydrodesulfurization. Appl Catal A 240:29-40. https://doi.org/10.1016/S0926-860X(02)00417-9

18. Méndez FJ, Bastardo-González E, Betancourt P, Paiva L, Brito JL (2014) NiMo/MCM-41 catalysts for the hydrotreatment of polychlorinated biphenyls. Catal Lett 143:93-100. https://doi. org/10.1007/s10562-012-0933-y

19. Rodríguez-Castellón E, Jiménez-López A, Eliche-Quesada D (2008) Nickel and cobalt promoted tungsten and molybdenum sulfide mesoporous catalysts for hydrodesulfurization. Fuel 87:1195-1206. https://doi.org/10.1016/j.fuel.2007.07.020

20. Jaroszewska K, Lewandowski M, Grzechowiak JR, Szyja B (2011) Hydrodesulphurisation of 4,6-dimethyldibenzothiophene over NiMo catalysts supported on Ti(Al) modified MCM-41. Catal Today 176:202-207. https://doi.org/10.1016/j.cattod.2011.01.013

21. Mendez FJ, Franco-López OE, Bokhimi X, Solís-Casados DA, Escobar-Alarcón L, Klimova TE (2017) Dibenzothiophene hydrodesulfurization with NiMo and CoMo catalysts supported on niobium-modified MCM-41. App Catal B: Environ 219:479-491. https://doi.org/10.1016/j.apcatb.2017.07.079

22. Salas P, Wang JA, Armendariz H, Angeles-Chavez C, Chen LF (2009) Effect of the Si/Zr molar ratio on the synthesis of Zr-based mesoporous molecular sieves. Mater Chem Phys 114:139-144. https://doi.org/10.1016/j.matchemphys.2008.08.086

23. Stober W, Fink A (1968) Controlled growth of monodisperse silica spheres in the micron size range. J Colloid Interface Sci 26:62-69. https://doi.org/10.1016/0021-9797(68)90272-5 
24. La-Salvia N, Lovón-Quintana JJ, Pagani Lovóna AS, Paim Valença $G$ (2017) Influence of aluminum addition in the framework of MCM-41 mesoporous molecular sieve synthesized by non-hydrothermal method in an alkali-free system. Mater Res 20:1461-1469. https://doi.org/10.1590/1980-5373-mr-2016-1064

25. Cassiers K, Linssen T, Mathieu M, Benjelloun M, Schrijnemakers K, Van Der Voort P, Cool P, Vansant EF (2002) Detailed study of thermal, hydrothermal, and mechanical stabilities of a wide range of surfactant assembled mesoporous silicas. Chem Mater 14:2317-2324. https://doi.org/10.1021/cm0112892

26. Garbowskit DE, Mirodatos C (1982) Investigation of structural charge transfer in zeolites by UV spectroscopy. J Phys Chem 86:97-102. https://doi.org/10.1021/j100390a019

27. Zanjanchi MA, Razavi A (2001) Identification and estimation of extra-framework aluminium in acidic mazzite by diffuse reflectance spectroscopy. Spectrochim Acta A 57:119-127. https://doi. org/10.1016/S1386-1425(00)00339-5

28. Zanjanchi MA, Asgari S (2004) Incorporation of aluminum into the framework of mesoporous MCM-41: the contribution of diffuse reflectance spectroscopy. Solid State Ion 171:277-282. https ://doi.org/10.1016/j.ssi.2004.05.005

29. Baltes M, Cassiers K, Van Der Voort P, Weckhuysen BM, Schoonheydt RA, Vansant EF (2001) MCM-48-supported vanadium oxide catalysts, prepared by the molecular designed dispersion of $\mathrm{VO}(\mathrm{acac})_{2}$ : a detailed study of the highly reactive MCM-48 surface and the structure and activity of the deposited $\mathrm{VO}_{\mathrm{x}}$. J Catal 197:160-171. https://doi.org/10.1006/jcat.2000.3066

30. Naydenov V, Tosheva L, Sterte J (2002) Spherical silica macrostructures containing vanadium and tungsten oxides assembled by the resin templating method. Microporous Mesoporous Mater 55:253-263. https://doi.org/10.1016/S1387-1811(02)00427-4

31. Haskouri JE, Cabrera S, Guillem C (2002) Atrane Precursors in the one-pot surfactant-assisted synthesis of high zirconium content porous silicas. Chem Mater 14:5015-5022. https://doi. org $/ 10.1021 / \mathrm{cm} 020131 \mathrm{u}$

32. Du Y, Sun Y, Di Y, Zhao L, Liu S, Xiao FS (2006) Ordered mesoporous sulfated silica-zirconia materials with high zirconium contents in the structure. J Porous Mat 13:163-171. https://doi. org/10.1007/s10934-006-7026-5
33. Bachari K, Chebout R, Guerroudj RM, Lamouchi M (2012) Preparation and characterization of Zr-MCM-41 synthesized under microwave irradiation condition for acetylation of 1,2-dimethoxybenzene with acetic anhydride. Res Chem Intermed 38:367-381. https://doi.org/10.1007/s11164-011-0353-4

34. Rodríguez-Castellón E, Jiménez-López A, Maireles-Torres P (2003) Textural and structural properties and surface acidity characterization of mesoporous silica-zirconia molecular sieves. J Solid State Chem 175:159-169. https://doi.org/10.1016/S0022 $-4596(03) 00218-4$

35. Ramanathan A, Castro VMC, Kwakernaak C, Telalovic S, Hanefeld U (2008) Zr-TUD-1: a Lewis acidic, three-dimensional, mesoporous, zirconium-containing catalyst. Chem Eur J 14:961972. https://doi.org/10.1002/chem.200700725

36. Dai LX, Tabata K, Suzuki E, Tatsumi T (2001) Synthesis and characterization of V-SBA-1 cubic mesoporous molecular sieves. Chem Mater 13:208-212. https://doi.org/10.1021/cm0005844

37. Kumar SN, Raman MS, Chandrasekaran J, Priya R, Chavali M, Suresh R (2016) Effect of post-growth annealing on the structural, optical and electrical properties of $\mathrm{V}_{2} \mathrm{O}_{5}$ nanorods and its fabrication, characterization of $\mathrm{V}_{2} \mathrm{O}_{5} / \mathrm{p}-\mathrm{Si}$ junction diode. Mater Sci Semicond Process 41:497-507. https://doi.org/10.1016/j. mssp.2015.08.020

38. Silva-Rodrigo R, Calderon-Salas C, Melo-Banda JA, Dominguez JM, Vázquez-Rodríguez A (2004) Synthesis, characterization and comparison of catalytic properties of NiMo- and NiW/TiMCM-41 catalysts for HDS of thiophene and HVGO. Catal Today 98:123-129. https://doi.org/10.1016/j.cattod.2004.07.026

39. Guillard C, Lacroix M, Vrinat M, Breysse M, Mocaer B, Grimblot J, des Courieres T, Faure D (1990) Preparation, characterization and catalytic properties of unsupported vanadium sulphides. Catal Today 7:587-600. https://doi.org/10.1016/0920-5861(90)80010 $-\mathrm{M}$

Publisher's Note Springer Nature remains neutral with regard to jurisdictional claims in published maps and institutional affiliations. 